\title{
Determinan Pernikahan Usia Muda pada Wanita Desa Gampong Pukat Kecamatan Pidie Kabupaten Pidie
}

\author{
The Determinants of Early Married in Rural Area Gampong Pukat Pidie \\ District
}

\author{
Asmaul Husna*1 ${ }^{1}$ Zarfiel Tafaal ${ }^{2}$ \\ ${ }^{1}$ Program Studi D-IV Kebidanan, Fakultas Ilmu Kesehatan Universitas Ubudiyah Indonesia, Banda Aceh, Indonesia \\ ${ }^{2}$ Program Studi Ilmu Kesehatan Masyarakat, Fakultas Ilmu Kesehatan Universitas Indonesia, Jl. Margonda Raya, Pondok \\ Cina, Beji, Kota Depok, Jawa Barat \\ *Korespondensi Penulis : asmaulhusna@uui.ac.id
}

\begin{abstract}
Abstrak
Pernikahan usia muda merupakan masalah di Indonesia. Batas usia pernikahan usia sehat adalah usia 25 tahun untuk laki-laki dan 20 tahun untuk perempuan. Dalam (SDKI) 2007, dari 6.341 perempuan usia 15-19 tahun, $12,8 \%$ dari mereka sudah menikah dan dari 6.681 perempuan usia 20-24 tahun, 59\% diantaranya sudah menikah. Ini merupakan penelitian kuantitatif non-eksperimental dengan pengumpulan data secara cross sectional. Analisis univariat hanya melihat distribusi frekuensi dan persentase setiap variabel. Analisis bivariat menggunakan uji chi square dengan CI (Confident Interval) 95\% dan analisis multivariat menggunakan regresi logistik. dilakukan di Desa Kampong Pukat Kecamatan Pidie Kabupaten Pidie pada bulan Desember Tahun 2015, dengan populasi seluruh pasangan yang sudah menikah yaitu sebanyak 50 istri. Dan semua anggota populasi dijadikan responden. Hasil penelitian diperoleh bahwa ada hubungan pengetahuan ( $p$-Value $=0,012$, OR $=0,159)$, variabel pekerjaan $(p$-Value $=0,010, \mathrm{OR}=5,667)$, variabel dorongan orang tua ( $p$-Value $=0,035$, OR $=5,333)$ berhubungan dengan pernikahan di usia muda. Penelitian ini menemukan bahwa ada hubungan variable pengetahuan dan pekerjaan yang termasuk faktor predisposing berhubungan bermakna dengan pernikahan usia muda dan dorongan orang tua berhubungan bermakna dengan pernikahan di usia muda. Dari analisis multivariat diperoleh hasil bahwa pengetahuan merupakan variabel yang paling dominan terhadap pernikahan usia muda setelah di control oleh variable dorongan orang tua, pekerjaan dan pendidikan.
\end{abstract}

Kata kunci : Pernikahan Usia Muda, Pengetahuan, Pekerjaan, Dorongan Orang Tua

\section{Abstract}

Early married is a problem in Indonesia. The line of age for married is 25 years old for men and 20 years for women. In (SDKI) 2007, from 6,341 women 15-19 years old, $12.8 \%$ of them are married and from 6,681 women 20-24 years old, 59\% of whom are married. This is a non-experimental quantitative research with cross sectional data collection. The univariate analysis only see a frequency distribution and percentage of each variable. Bivariate analysis using chi square test with CI (Confident Interval) 95\%, and multivariate logistic regression. The research are conducted in the village Gampong Pukat Pidie district in December 2015, the populations are couples as many as 50 wives. And all members of the population are respondents. The result showed that there is a relationship of knowledge ( $p$ Value $=0.012$, 
$O R=0.159)$, variable job ( $p$ Value $=0.010, O R=5.667)$, variable parents' support (p Value $=0.035$, OR $=5.333$ ) with early-age married. This study found that there is a correlation variable knowledge and work including predisposing factor significantly related to early married and urge parents significantly related to early married. Multivariate analysis showed that the knowledge is the most dominant variable toward marriage at early married after control by variable parents' Encouragement, employment and education.

Keyword: Knowledge, Employment, Parents' Encouragement

\section{PENDAHULUAN}

Pernikahan usia muda merupakan pernikahan di bawah umur yang seharusnya belum saatnya untuk melaksanakan pernikahan. Batas usia pernikahan usia sehat adalah usia 25 tahun untuk laki-laki dan 20 tahun untuk perempuan. Dalam aspek pernikahan, Survei Demografi dan Kesehatan Indonesia (SDKI) 2007 melaporkan bahwa dari 6.341 perempuan usia 15-19 tahun, 12,8\% dari mereka sudah menikah dan dari 6.681 perempuan usia 20-24 tahun, 59\% diantaranya sudah menikah. Usia 15-24 tahun oleh UNFPA dianggap sebagai pemuda dan 15-19 tahun sebagai remaja akhir, sehingga jelas bahwa remaja berdasarkan SDKI 2007 menikah pada usia yang lebih muda.Menurut survey tahun 2005 terdapat 21,5\% wanita di Indonesia yang perkawinan pertamanya dilakukan ketika berusia 17 tahun.

Di daerah pedesaan dan perkotaan wanita melakukan perkawinan dibawah umur tercatat masing-masing $24,4 \%$ dan $16,1 \%$. Persentase tersebar kawin muda terdapat diProvinsi Jawa Timur 90,3\%, Jawa Barat 39,6\% dan Kalimantan Selatan 37,5\%. Serta pernikanan dini berkisar 12-20\% yang dilakukan oleh pasangan baru. Biasanya, pernikahan dini dilakukan pada pasangan usia muda rata-rata umumnya antara 16-20 tahun. Secara Nasional pernikahan dini dengan usia pengantin dibawah usia 16 tahun sebanyak 26,95\% (Disdukpencapil.RI,2005).

Menurut data dari KUA Kecamatan Pidie Kabupaten Pidie tahun 2013 dari 205 orang pasangan yang menikah dan tercatat $23(11,2 \%)$ orang pasangan yang menikah muda. Pada tahun 2014 dari orang 200 pasangan yang menikah, tercatat 24 (12\%) orang pasangan yang menikah muda. Pada tahun 2015 dari bulan Januari sampai bulan Agustus tercatat dari 216 orang pasangan yang menikah, tercatat $70(32,4 \%)$ pasang menikah muda. Sedangkan di Desa Kampong Pukat Kecamatan Pidie Kabupaten Pidie tercatat 50 pasangan istri yang menikah, dan yang melakukan pernikahan di usia dini tercatat 20 pasang yang menikah muda. 


\section{METODE PENELITIAN}

Jenis penelitian ini adalah penelitian survey yang bersifat deskriptif analitik. Penelitian ini merupakan kuantitatif non-eksperimental dengan pengumpulan data secara cross sectional. Penelitian ini dilakukan di Desa Kampong Pukat Keacamatan Pidie Kabupaten Pidie pada bulan Desember tahun 2015. Waktu penelitian ini dilakukan pada bulan Desember tahun 2015. Populasi dalam penelitian ini adalah seluruh pasangan yang sudah menikah yaitu sebanyak 50 istri di Desa Kampong Pukat Kecamatan Pidie Kabupaten Pidie dan semua anggota populasi dijadikan responden.

\section{HASIL PENELITIAN}

Tabel 1. Hubungan Pengetahuan dengan Pernikhan Dini di Desa Kampong Pukat Kecamatan Pidie Kabupaten Pidie Tahun 2015

\begin{tabular}{|c|c|c|c|c|c|c|c|c|c|}
\hline \multirow{3}{*}{ No } & \multirow{3}{*}{ Pengetahuan } & \multicolumn{4}{|c|}{ Pernikahan Dini } & \multirow{3}{*}{ Total } & \multirow{3}{*}{$\%$} & \multirow{3}{*}{$\begin{array}{c}p \\
\text { value }\end{array}$} & \multirow{3}{*}{$\begin{array}{c}\text { OR } \\
(95 \% \mathrm{CI})\end{array}$} \\
\hline & & \multicolumn{2}{|c|}{$\mathbf{Y a}$} & \multicolumn{2}{|c|}{ Tidak } & & & & \\
\hline & & $\mathbf{n}$ & $\%$ & $\mathbf{n}$ & $\%$ & & & & \\
\hline 1. & Kurang & 11 & 32,4 & 23 & 67,6 & 34 & 100 & & 0,159 \\
\hline 2. & Baik & 12 & 75 & 4 & 25 & 16 & 100 & 0,012 & $\begin{array}{c}(0,042- \\
0,609)\end{array}$ \\
\hline
\end{tabular}

Hasil analisis hubungan antara pengetahuan dengan pernikahan di usia muda bahwa ada sebanyak 34 responden yang berpengetahuan kurang di dapat yang tidak menikah di usia muda sebanyak 67,6\% dibandingkan dari 16 responden yang berpengetahuan baik di dapat yang menikah di usia muda sebanyak 25\%. Hasil uji statistik yang diperoleh $p$ Value 0,012 maka disimpulkan bahwa ada hubungan yang signifikan antara pengetahuan dengan pernikahan di usia muda. Dengan OR 0,159 artinya responden dengan pengetahuan yang rendah mempunyai peluang 0,159 kali untuk melakukan pernikahan di usia muda.

Tabel 2. Hubungan Pekerjaan dengan Pernikhan Dini di Desa Kampong Pukat Kecamatan Pidie Kabupaten Pidie Tahun 2015

\begin{tabular}{llcccccccc}
\hline & \multicolumn{4}{c}{ Pernikahan Dini } & & & $\boldsymbol{p}$ & OR \\
No & \multirow{2}{*}{ Pekerjaan } & \multicolumn{2}{c}{ Ya } & \multicolumn{2}{c}{ Tidak } & Total & \% & Value & (95\% CI) \\
& & n & \% & n & \% & & & & \\
\hline 1. & Tidak Bekerja & 17 & 65,4 & 9 & 34,6 & 26 & 100 & & 5,667 \\
2. & Bekerja & 6 & 25 & 18 & 75 & 24 & 100 & & $19,336)$ \\
\hline
\end{tabular}


Hasil analisis hubungan antara pekerjaan dengan pernikahan di usia muda bahwa ada sebanyak 26 responden yang orang tuanya tidak bekerja di dapat yang menikah di usia muda sebanyak 65,4\% di bandingkan dari 24 responden yang orang tuanya bekerja di dapat yang tidak menikah di usia muda sebanyak $75 \%$. Hasil uji statistik yang diperoleh $p$ Value 0,010 maka disimpulkan bahwa ada hubungan yang signifikan antara pekerjaan orang tua dengan pernikahan di usia muda. Dengan OR 5,667 artinya responden yang orang tuanya tidak bekerja akan mempunyai peluang 5,667 kali untuk melakukan pernikahan di usia muda.

Tabel 3. Hubungan Dorongan Orang Tua dengan Pernikahan Dini di Desa Kampong Pukat Kecamatan Pidie Kabupaten Pidie Tahun 2015

\begin{tabular}{llcccccccc}
\hline & \multicolumn{4}{c}{ Pernikahan Dini } & & \multicolumn{2}{c}{$\boldsymbol{p}$} & OR \\
\multirow{2}{*}{ No } & Dorongan & \multicolumn{2}{c}{ Ya } & \multicolumn{2}{c}{ Tidak } & Total & \% & Value & (95\% CI) \\
& Orang Tua & $\mathbf{n}$ & $\%$ & $\mathbf{n}$ & $\boldsymbol{\%}$ & & & \\
\hline 1. & Tidak & 20 & 57,1 & 15 & 42,9 & 35 & 100 & & 5,333 \\
2. & Ada & 3 & 20 & 12 & 80 & 15 & 100 & & $22,317)$ \\
\hline
\end{tabular}

Hasil analisis hubungan antara dorongan orang dengan pernikahan di usia muda bahwa ada sebanyak 35 responden yang tidak mendapatkan dorongan orang tua di dapat yang menikah di usia muda sebanyak 57,1\%, di bandingkan dari 15 responden yang mendapatkan dorongan orang tua di dapat yang tidak menikah di usia muda sebanyak $80 \%$.Hasil uji statistik yang diperoleh $p$ Value 0,035 maka disimpulkan bahwa ada hubungan yang signifikan antara dorongan orang tua dengan pernikahan di usia muda. Dengan OR 5,333 artinya responden yang mempunyai dorongan orang tua akan mempunyai peluang 5,333 kali untuk melakukan pernikahan di usia muda.

Tabel 4. Analisis Multivariat Pemodelan Terakhir

\begin{tabular}{|c|c|c|}
\hline Variabel & p Value & OR \\
\hline Pengetahuan & 0,043 & 0,156 \\
\hline Pendidikan & 0,059 & 8,453 \\
\hline Pekerjaan & 0,065 & 3,909 \\
\hline Dorongan orang tua & 0,119 & 3,482 \\
\hline
\end{tabular}

Interpretasi dilakukan berdasarkan nilai OR pada masing-masing variabel, karena hasil analisisnya multivariat maka OR-nya sudah terkontrol oleh variabel lain yang ada pada model. Setelah dilakukan pengujian sebanyak 3 kali, maka didapatkan model terbaik variabel 
yang berhubungan dengan pernikahan di usia muda yaitu pengetahuan. Hal ini berarti responden yang pernah mendapatkan pengetahuan yang baik terkait pernikahan usia muda 0,156 kali lebih mengerti akan bahaya dari pernikahan usia muda setelah dikontrol oleh variabel pendidikan, pekerjaan, dan dorongan orang tua.

\section{Pembahasan}

1. Hubungan Pengetahuan dengan Pernikahan Usia Muda

Hasil analisis hubungan antara pengetahuan dengan pernikahan di usia muda bahwa ada sebanyak 34 responden yang berpengetahuan kurang di dapat yang tidak menikah di usia muda sebanyak 67,6\% dan dari 16 responden yang berpengetahuan baik di dapat yang menikah di usia muda sebanyak 25\%. Hasil uji statistik yang diperoleh pValue 0,012 maka disimpulkan bahwa ada hubungan yang signifikan antara pengetahuan dengan pernikahan di usia muda. Dengan OR 0,159 artinya responden dengan pengetahuan yang rendah mempunyai peluang 0,159 kali untuk melakukan pernikahan di usia muda.Hasil penelitian Rahardjo,dkk (2012), bahwa terdapat hubungan signifikan antara pengetahuan pernikahan usia muda ( $p$ value $=0,000$ ) dan $\mathrm{OR}=3,71$. Dengan demikian hasi uji statistik penelitian ini diketahui bahwa responden yang berpengetahuan kurang memiliki resiko melakukan pernikahan dini 2,23 kali lebih besar dibandingakan dengan yang berpengetahuan baik.

Menurut Adi (2004), pengetahuan diartikan sebagai kesan di dalam pikiran manusia sebagai hasil penggunaan panca indra. Pengetahuan bertujuan untuk mendapatkankepastian dan menghilangkan prangka ketidakpastian.Pengetahuan sangat mempengaruhi dalam prospek kehidupan, terlebih terhadap kaum wanita, kurangnya pengetahuan dapat mengakibatkan terjadinya pernikahan dini.Pengetahuan tentang kehamilan merupakan hal penting yang harus diperhatikan setelah menikah, termasuk remaja putri yang menikah dini. Dengan pengetahuan tentang kehamilan yang cukup wanita akan lebih siap menghadapi kehamilan dan tidak mudah mengalami kecemasan. Pengetahuan berhubungan dengan jumlah informasi yang dimiliki seseorang (Stuart \& Sundeen, 2001).

Perempuan yang menikah di usia dini kurang dari 15 tahun memiliki banyak risiko, sekalipun ia sudah mengalami menstruasi atau haid. Ada dua dampak medis yang ditimbulkan oleh pernikahan usia dini ini, yakni dampak pada kandungan dan kebidanannya. penyakit kandungan yang banyak diderita wanita yang menikah usia dini, antara lain infeksi pada kandungan dan kanker mulut rahim. Hal ini terjadi karena 
terjadinya masa peralihan sel anak-anak ke sel dewasa yang terlalu cepat. Padahal, pada umumnya pertumbuhan sel yang tumbuh pada anak-anak baru akan berakhir pada usia 19 tahun. Hal tersebut akan sangat rentan terjadi kepada mereka yang menikah usia muda.

Risiko kesehatan terutama terjadi pada pasangan wanita pada saat mengalami kehamilan dan persalnan. Kehamilan mempunyai dampak negative terhadap kesejahteraan seorang remaja. Sebenarnya ia belum siap mental untuk hamil, namun karena keadaan ia terpaksa, menerima kehamilan risiko tinggi.Hasil penelitian di atas membuktikan bahwa pengetahuan seseoraang sangat berpengaruh terhadap terjadinya pernikahan dini. Dalam hal ini diharapkan bagiterkait yang ada di Desa Kampong Pukat yaitu petugas kesehatan dapat memberikan informasi kesehatan tentang kesehatan reproduksi.Pemberian ini bisa melalui penyuluhan disekolah-sekolah, penyebaran pamphlet, brosur dan lain sebagainya.Agar dapat meningkatkan pengetahuan wanita khususnya di daerah penelitian.

\section{Hubungan Pekerjaan dengan Pernikahan Usia Muda}

Hasil analisis hubungan antara pekerjaan dengan pernikahan di usia muda bahwa ada sebanyak 26 responden yang orang tuanya tidak bekerja di dapat yang menikah di usia muda sebanyak $65,4 \%$ dan dari 24 responden yang orang tuanya bekerja di dapat yang tidak menikah di usia muda sebanyak 75\%. Hasil uji statistik yang diperoleh pValue 0,010 maka disimpulkan bahwa ada hubungan yang signifikan antara pekerjaan orang tua dengan pernikahan di usia muda. Dengan OR 5,667 artinya responden yang orang tuanya tidak bekerja akan mempunyai peluang 5,667 kali untuk melakukan pernikahan di usia muda.

Hasil penelitian Rahardjo,dkk (2012) bahwa pekerjaan ada hubungan yang signifikan antara pekerjaan dengan pernikahan di usia muda dengan p value $=0,027$. Berdasarkan hasil tersebut diketahui bahwa pekerjaan merupakan salah satu faktor yang mempengaruhi pernikahan di usia muda.Selain itu belum lagi masalah ketenaga kerjaan, seperti realita yang ada didalam masyarakat, seseorang yang mempunyai pendidikan rendah hanya dapat bekerja sebagai buruh saja, dengan demikian dia tidak dapat mengeksplor kemampuan yang dimilikinya. Oleh karena itu dengan menikah di usia muda maka dapat meringankan beban ekonomi menjadi lebih hemat.

Pekerjaan orang tua saat anaknya belum menikah sangat berpengaruh dikarenakan orang tua yang tidak mempunyai pekerjaan akan semakin cepat menikahkan anaknya, karena orang tua tidak mampu membiayai hidup anaknya, sehingga orang tua menikahkan 
anaknya agar kehidupan keluarga daan anaknya menjadi lebih baik. Oleh karena itu diharapkan kepada instansi terkait di Desa Kampong Pukat agar membuat sosialisasi terkait lapangan kerja yang dapat di manfaatkan oleh warga Desa setempat.

\section{Hubungan Dorongan Orang Tua dengan Pernikahan Usia Muda}

Hasil analisis hubungan antara dorongan orang dengan pernikahan di usia muda bahwa ada sebanyak 35 responden yang tidak mendapatkan dorongan orang tua di dapat yang menikah di usia muda sebanyak $57,1 \%$, dan dari 15 responden yang mendapatkan dorongan orang tua di dapat yang tidak menikah di usia muda sebanyak $80 \%$. Hasil uji statistik yang diperoleh pValue 0,035 maka disimpulkan bahwa ada hubungan yang signifikan antara dorongan orang tua dengan pernikahan di usia muda. Dengan OR 5,333 artinya responden yang mempunyai dorongan orang tua akan mempunyai peluang 5,333 kali untuk melakukan pernikahan di usia muda.

Hasil penelitian ini sejalan dengan hasil penelitian yang dilakukan oleh Maryatun (2010) bahwa peran orang tua dalam mencarikan dan menentukan pasangan hidup anaknya perempuannya (terutama pada perkawinan pertama) umumnya ditemukan dikalangan masyarakat Jawa, terlebih lagi di daerah pedesaan.Selain itu dapat juga keluarga atau orang tua yang mendorong mereka untuk melakukan hal tersebut, oleh karena itu melihat fenomena tersebut di masyarakat.

Bukan tidak mungkin pernikahan dini yang terjadi di masyarakat juga terjadi di desaa-desa.Orang tua merasa khawatir kena aib karena anak perempuannya berpacaran dengan laki-laki yang sangat lengket sehingga segera mengawinkan anaknya. Hal ini bisa terjadi pada suatu pasangan yang sudah saling cinta dan mungkin tidak bisa dipisahkan sehingga keduanya melakukan perkawinan usia muda dengan tujuan menghindari perzinaan atau sex bebas.Dari hasil yang di dapat di atas terdapat hubungan antara dorongan orang tua dengan pernikahan di usia muda karena orang tua yang takut anaknya berbuat hal yang tidak diinginnka. Oleh karena itu orang tua harus selalu membimbing anaknya ke hal-hal yang positif.

\section{KESIMPULAN}

Hampir setengah responden menikah usia muda yaitu sebanyak $46 \%$ sedangkan yang tidak meikah usia muda yaitu sebanyak 54\%.Variabel pengetahuan dan pekerjaan yang 
merupakan faktor predisposing berhubungan bermakna dengan pernikahan usia muda.Tidak ada hubungan antara faktor pemungkin dengan pernikahan di usa muda.Variabel dorongan orang tua berhubungan bermakna dengan pernikahan di usia muda.Pengetahuan merupakan variabel yang paling dominan terhadap pernikahan usia muda setelah di kontrol oleh variabel dorongan orang tua, pekerjaan dan pendidikan

\section{SARAN}

Pihak Kantor Urusan Agama Pihak Kantor Urusan Agama agar dapat menginformasikan tentang akibat yang akan terjadi akibat pernikahan usia muda pada wanita, karena akan berakibat pada kesehatan reproduksi dan akan mengakibatkan terjadinya keluarga yan tidak tidak harmonis, oleh karena itu pihak Kantor Urusan Agama harus benar-benar memberi juga informasi kepada orang tua yang akan menikahkan anaknya di usia muda.Pihak Kantor Kepala Desa Pihak Kantor Kepala Desa agar dapat mememberi informasi melalui bantuan pihak kesehatan akan bahaya dari akibat pernikahan di usia muda, dan juga agar dapat membuka lapangan kerja yang baik bagi para orang tua agar perekonomian keluarga bisa lebih membaik.

\section{DAFTAR PUSTAKA}

Adi R. 2004. Metodologi Penelitian Sosial dan Hukum, Jakarta,

Disdukpencapil RI, 2005. Profil Kejadian Pernikahan Usia Muda di Indonesia, Jakarta

Karjono. 2014, Penyebab Terjadinya Pernikahan Dini Pada Remaja, Vol 8, No 7, Desember 2014 (16 Januari 2016). Kawakib . 2009, Kesehatan Reproduksi Remaja, Jogjakarta, EGC)

Lenteraim, 2010, Pernikahan Usia Muda. (http://lenteraim.com), di akses pada tanggal 2 November 2015.

Luthfiyah.2008, Pernikahan Dini Pada Kalangan Remaja (15-19 Tahun), (http://nyna0626.com) di akses pada tanggal 2 November 2015.

Maryatum, 2010, http://PengaruhDorongan org tua Terhadap Terjadinya Pernikahan Dini.com (dikutip tanggal 2 November 2015).

Raharjo, imron.Determinan Pernikahan dini di Kecamatan Kalianda (artikel kesehatan).Jurnal Kesehatan, Volume IV, Nomor 2,Oktober 2013, hlm 357-363.

SDKI, 2007.Profil Kesehatan Reproduksi Indonesia, Jakarta

Stuart dan Sundeen.(2001). Buku saku keperawatan Jiwa (Edisi ketiga). Jakarta: EGC. 